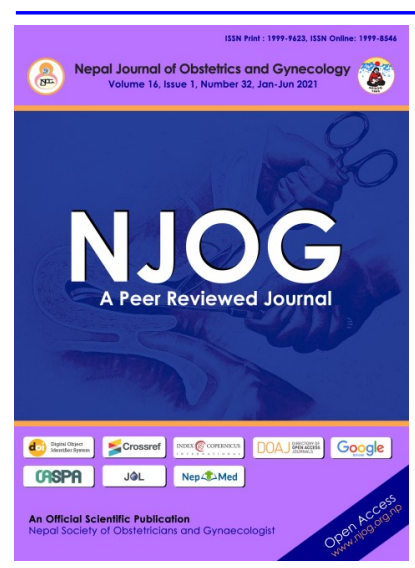

CORRESPONDENCE

Dr Arjun Prasad Tiwari

Karnali Academy of Health Sciences, Jumla, Nepal

Email:

arjunsep20@gmail.com;

Phone: +977-9851184421

Received: April 15, 2020

Accepted: May 1, 2021

\section{Citation:}

Tiwari AP, Shrestha AB, Pradhan R, Baral BK, Gurung T, Shrestha S. Correlation of palpation versus ultrasound-assisted approach for locating the leve of lumbar puncture used for subarachnoid block in elective cesarean delivery. Nep J Obstet Gynecol. 2021;16 (32):73-76. DOI: https:// doi.org/10.3126/ njog.v16i1.37608

\title{
Correlation of palpation versus ultrasound-assisted approach for locating the level of lumbar puncture used for subarachnoid block in elective cesarean delivery
}

\author{
Arjun Prasad Tiwari, ${ }^{1}$ Amir Babu Shrestha, ${ }^{2}$ Ritu Pradhan, ${ }^{1}$ Bidur Kumar \\ Baral, ${ }^{1}$ Tara Gurung, ${ }^{2}$ Sangeeta Shrestha ${ }^{2}$ \\ ${ }^{1}$ National Academy of Medical Sciences (NAMS), Bir Hospital ${ }^{2}$ Paropa- \\ kar Maternity and Women's Hospital, Kathmandu
}

\section{ABSTRACT}

Aims: To correlate the level of lumbar puncture used for subarachnoid block in parturient undergoing elective cesarean delivery between palpation and ultrasound method; and to find its accuracy.

Methods: This is an observational study, conducted in 314 parturient undergoing elective caesarean delivery under spinal anesthesia over the period of three months at Paropakar Maternity and Women's Hospital Kathmandu. The interspinous space identified by palpation method on lateral position for subarachnoid block and later the site confirmed by ultrasound.

Results: In this study, intervertebral space identified by palpation was matched in $38.1 \%$ (i.e. 107 in 281 patients) when assessed with ultrasound (USG). In $166(59.1 \%)$ patients, skin puncture level was determined by palpation was found to be one intervertebral space cephalic. In eight (2.8\%) patients, one intervertebral space caudal while assed with USG. The correlation between intervertebral space determined by palpation and by ultrasonography was poor (correlation coefficient $r=0.288$ ). The kappa was $0.293 \pm 0.015$.

Conclusions: The level of lumbar puncture used for subarachnoid block in elective cesarean delivery by palpation method is poorly correlated $(38.1 \%)$ with ultrasonographic identification of corresponding interspinous level.

Keywords: elective cesarean delivery, subarachnoid block, ultrasound

\section{INTRODUCTION}

Cesarean delivery is one of the most commonly performed surgeries in obstetrics. Cesarean section is generally carried out under Subarachnoid Block (SAB). It produces a quick sensory and good motor block through the injection of local anesthetic to the subarachnoid space. With the use of SAB, Maternal mortality and morbidity were significantly reduced in obstetric anesthesia. ${ }^{1,2}$ Tuffier line is an imaginary horizontal line joining the two superior parts of the posterior iliac crests. It passes through the L4 vertebral body. This is commonly used surface landmark for the identification of intervertebral space (IVS) for neuraxial block and it is identified by palpation. Palpation is shown to be least reliable method with accuracy rate being as low as $29 \%{ }^{3}$

A full term parturient undergoes various physical changes including weight gain, pelvic rotation, hyperlordosis, and tissue edema. ${ }^{4}$ Many studies have found that anesthesiologist select interspinous spaces one or two spaces higher than their intended selected space $^{5}$ and it increases the incidence of severe neurological trauma after spinal anaesthesia. There are numerous case reports of spinal cord injury during subarachnoid block for cesarean delivery. ${ }^{6-8}$ So there is appropriate concern of neurological injury with using landmarks technique. In recent years, Neuraxial ultrasound is commonly used in regional anaesthesia practice. ${ }^{9}$ The ultrasound helps in correct 
identification of the lumbar interspinous space. The study done by Watson et $\mathrm{a}^{10}$ found that the success rate was $76 \%$ with ultrasound to identify the lumbar interspinous space.

Hence, this study was designed to find out correlation of lumbar puncture used for subarachnoid block in parturient undergoing elective cesarean delivery between by palpation method with ultrasound.

\section{METHODS}

This is a prospective observational study, conducted in parturient undergoing elective caesarean delivery under spinal anesthesia (SAB) over the period of three months in Paropakar Maternity and Women's Hospital, a tertiary level public hospital in Nepal, from $16^{\text {th }}$ July to $17^{\text {th }}$ September 2017 . Ethical approval was obtained from the hospital IRC. Before enrolling in the study, informed written consent was taken. Cases with single term cesarean delivery, ASA physical status grade II were enrolled in this study. Patient having allergies to study drugs, local infection, multiple puncture at different level, patient having contraindication to spinal anesthesia were excluded.

The patient was kept in left lateral position, parallel to the edge of the operation table. The interspinous space L3-L4 was identified by using landmark technique, after cleaning and draping the subarachnoid block was given. The puncture site was marked by permanent sterile skin marker and documented it. After completion of surgery patient shifted to the recovery room. Another anesthesiologist who is blind to the marked needle puncture site was performed ultrasound scan in left lateral position. U1trasound probe was placed over the sacral area in the transverse axis. Sacrum was taken as a reference landmark which appears as a horizontal hyperechogenic line. Then probe was moved into cephalad direction to identify the spinous process of each lumbar vertebra. The hyper-echogenic pattern corresponding to the laminae of vertebra white hypoechogenic shadow corresponding inter-vetebral space forms a saw tooth like pattern. For accurate counting of interspinous space, each space corresponding to the center of probe was marked on skin.

The primary outcome was to find out the accuracy of the skin puncture level, determined by palpation with ultrasound. Secondary outcome was to observe the skin puncture level, higher or lower than their intended selected vertebral level by palpation.
Data analyzed using SPSS 20 and expressed in descriptive parameter for age and BMI; and logistic regression analysis tool was used to assess the correlation between identification of the lumbar interspinous spaces by palpation and ultrasound imaging. The agreement between palpation method and ultrasound assessment of IVS was analyzed using kappa statistic. The p-value $<0.05$ was defined as statistical significance.

\section{RESULTS}

Three hundred fourteen parturient had taken consent to participated in this study. However, thirtythree women were excluded because ten patients had incomplete medical records, and 23 women had multiple needle insertion marks on their back. So only two hundred eighty-one parturient women were included for analysis. Among them, the age range from 16 to $38(25.91 \pm 4.419)$ years. The body mass index (BMI) ranges from 21 to 45 (28.29 \pm 3.612$)$.

The level of the puncture mark documented by the anesthesiologist by palpation at $\mathrm{L}_{3}-\mathrm{L}_{4}$ was 274 and $\mathrm{L}_{4}-\mathrm{L}_{5}$ in 7. Among them only in 107 (38.1\%) patients, the level of the puncture mark by palpation was matched with intervertebral space assessed by using ultrasound (USG). In 166 (59.1\%) patients, skin puncture level determined by palpation was found to be one intervertebral space cephalic. In eight $(2.8 \%)$ patients, inter space level documented in the anesthetic record was one intervertebral space caudal during USG examination (Table-1 and Figure-2). These Variables were evaluated by univariate and multivariate logistic regression analysis. There was significant disagreement between intervertebral space determined by palpation and ultrasonography. The correlation between two techniques for the estimation of intervertebral space was poor at $\mathrm{L}_{3}-\mathrm{L}_{4}$ (correlation coefficient, $\mathrm{r}=0.288$, kappa $=0.293 \pm 0.015$ ).

Table-1: Lumbar intervertebral space identified by palpation and USG

\begin{tabular}{lll}
\hline $\begin{array}{l}\text { Lumber inter- } \\
\text { vertebral }\end{array}$ & $\begin{array}{l}\text { sdentified by } \\
\text { Palpation }\end{array}$ & $\begin{array}{l}\text { Identified by Ultra- } \\
\text { sound imaging (\%) }\end{array}$ \\
\hline L2-L3 & 0 & $166(59.1 \%)$ \\
L3-L4 & $274(97.5 \%)$ & $107(38.1 \%)$ \\
L4-L5 & $7(2.5 \%)$ & $8(2.8 \%)$ \\
\hline
\end{tabular}

Palpatory accuracy of lumber spinal level is better on upper intervertebral spaces confirmed by ultra- 
sound. Numbers in the circles describe the percentage of patients and the solid diagonal line is the line of agreement between the two techniques.

(correlation coefficient $\mathrm{r}=0.288$, kappa $=0.293 \pm 0.015)$. [Figure1]

Figure-1: Comparison of interspinous level identified by palpation and by USG.

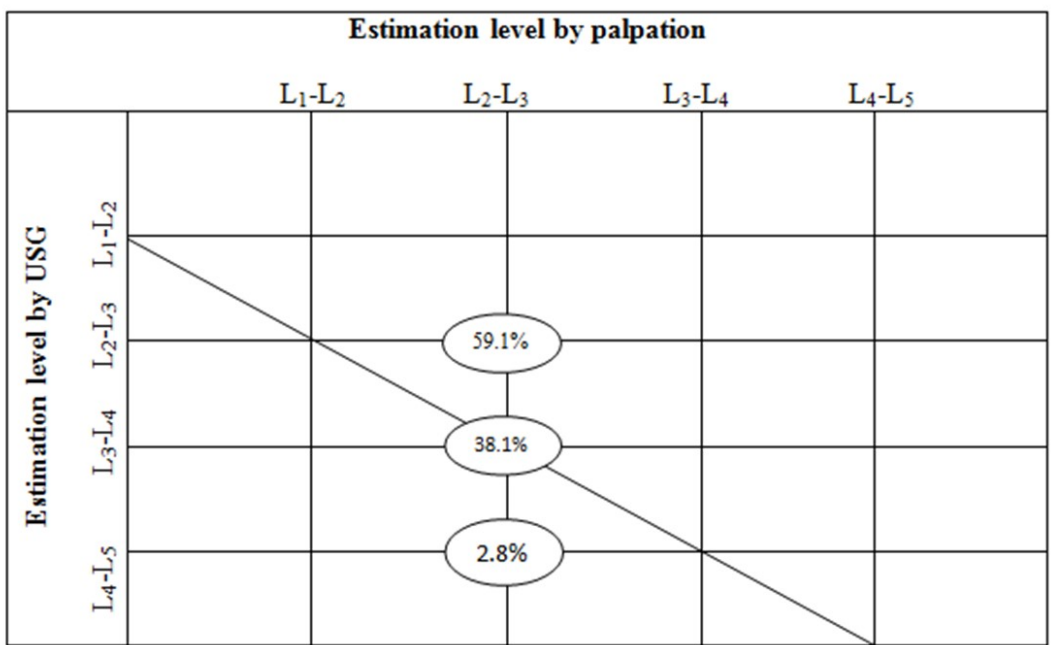

\section{DISCUSSION}

Correct identification of intervertebral space is essential for SAB. Traditionally, Tuffier's line, is used as an anatomical landmark, as it is believed to pass through the $\mathrm{L}_{4}$ vertebral body for the estimation of vertebral levels for central neuraxial block. ${ }^{11-13}$

The accuracy of palpation method to assess interspinous space was in between $29 \%$ to $64 \% .{ }^{14}$ In our study, the accuracy of interspinous space by palpation method was $38.1 \%$ when compared to ultrasound.

A similar study conducted by Parate et $\mathrm{a}^{15}$ the IVS located by palpation method was in agreement with ultrasound location in $37.14 \%$ of the patients and differs by 1-3 IVS in cephalad direction (53.31\%). The accuracy of palpation method with ultrasound is almost similar to our study. The accuracy is unaffected by age, sex height, and BMI.

Our findings are consistent with the finding of Schlotterbeck et $\mathrm{a}^{16}$, the clinical puncture level was accurate in $36.4 \%$ of patients. Ultrasound examination showed the puncture level to be more cephalad than the level noted in the anesthetic record in almost $50 \%$ of patients. In $15 \%$ of patients, the puncture level was more caudal than the anesthetist had assessed. In our study, the accuracy of interspinous space by palpation method was $38.1 \%$ when compared to ultrasound. Meanwhile In 59.1\% patients, the skin puncture level determined by palpation was one intervertebral space cephalic and in $2.8 \%$ it was one intervertebral space caudal in our study. The factors including type of anesthesia, indication, time spinal pathology did not seem to influence the frequency of errors.

A similar study that the level of the puncture mark was in agreement with the level estimated by postpartum ultrasound in $55 \%$. In $32 \%$, the skin puncture level estimated by ultrasound to be one interspace higher and in $12 \%$, interspace estimation was lower. ${ }^{17}$
Another study by Locks et al found that puncture mark matched in 53\% with the level estimated by postpartum ultrasound in non-obese patients. ${ }^{18}$ The findings of above are differing as compare to our study. These contradictory results might be justified by differences in their methodology, reference standard and competence of anaesthesiologist.

Likewise, in a study by Lee et $\mathrm{al}^{19}$ found that the accuracy of the spinal level of the intercristal line agreed with the ultrasound was $14 \%$. One level higher in $23 \%$ and two level higher in $25 \%$. The findings of above study are differing as compare to our study. This might be due to the use of different statistical tools for data analysis.

The palpated level being one spinal level higher in $22.7 \%$, two levels higher in $45.3 \%$, three levels higher in $16 \%$ and four level higher in $4 \%$ in a study by Chakraverty et al. ${ }^{20}$ These finding are different as compared to our study. This might be due to the high BMI of study population. In high BMI correlations between palpated and ultrasonography have been reported poor.

There was concurrence of intervertebral space identification between clinical and ultrasound examination in $64 \%$ among patients undergoing lower limb surgery reported by Duinec et al. ${ }^{2}$ Which is higher than our study might be justified by differences in studied population, methodology, references.

The accuracy of ultrasound assessment when compared to other techniques (i.e. computerized tomography scan, magnetic resonance imaging, $\mathrm{X}$ ray) has been reported as $68-76 \%$ but with training and experience, it can enhance up to $90 \%$. The ultrasound can be used bedside or at Operation Theater and assessment can be done in the same flexed position given for spinal anesthesia.

In obstetric patients the traditional methods of assessing the intervertebral level by palpation is not a reliable technique. The puncture points might be 
higher than the expected level. The correct identification vertebral levels are very important to avoid needle trauma to the spinal cord. When the vertebral level is misidentified during neuraxial block, the complications like; nerve root damage, spinal cord damage, cauda equina syndrome may occur. Our studies found that the selected interspinous spaces by palpation are found one spaces higher than their intended selected space. Ultrasonography provides more accurate than palpation in correctly identifying lumbar interspaces.

A limitation of this study is that the ultrasonography was done only in longitudinal approach. Both the longitudinal and transverse approaches should be used to assess the intervertebral space for future research.

\section{CONCLUSIONS}

The marked level of lumbar puncture used for subarachnoid block in elective cesarean delivery by palpation method is poorly correlated (38.1\%) with ultrasonographic identification of corresponding interspinous level. The selected interspinous space by palpation is more cephalic $(59.1 \%)$ than their intended selected space with Ultrasound.

\section{REFERENCES}

1. Liu SS, McDonald SB. Current issues in spinal anesthesia. Anesthesiology: J Am Societ Anesth. 200;94(5):888-906.

2. Cooper GM, McClure JH. Anesthesia chapter from saving Mothers' lives; reviewing maternal deaths to make pregnancy safer. Br J Anaesth. 2008;100(1):17-22.

3. Broadbent CR, Maxwell WB, Ferrie R, Wilson DJ, Gawne-Cain M, Russell R. Ability of anaesthetists to identify a marked lumbar interspace. Anesth. 2000;55(11):1122-6.

4. Wong CA, Nathan N. Spinal, epidural, and caudal anesthesia: Anatomy, physiology, and technique. In Chestnut's obstetric anesthesia: Principles and practice. 5th ed. Philadelphia: Mosby Elsevier; 2014. pp. 229-66.

5. Saifuddin A, Burnett SJ, White J. The variation of position of the conus medullaris in an adult population. A magnetic resonance imaging study. Spine. 1998;23(13):1452-6.

6. Palmer CM, Baysinger CL. Spinal cord trauma during subarachnoid anesthesia for cesarean delivery: A Case Report. A\&A Practice. 2019;12 (12):452-4.

7. Parry H. Spinal cord damage. Anaesth. 2001;56 (3):290.

8. Collier CB, Gatt SP. More reports of spinal cord damage by spinal needles. Anaesth Intens Care. 2002;30(4):532.
9. Furness G, Reilly MP, Kuchi S. An evaluation of ultrasound imaging for identification of lumbar intervertebral level. Anesth. 2002;57:277-8.

10. Watson MJ, Evans S, Thorp JM. Could ultrasonography be used by an anesthetist to identify a specified lumbar interspace before spinal anaesthesia? Br J Anaesth. 2003;90(4):509-11.

11. Render CA. The reproducibility of the iliac crest as a marker of lumbar spine level. Anaesth. 1996;51(11):1070-1.

12. Wattanaruangkowit $\mathrm{P}$, Lakchayapakorn $\mathrm{K}$. The position of the lumbar vertebrae in relation to the intercrestal line. J Med Assoc Thai. 2010;93 (11):1294-300.

13. Snider KT, Kribs JW, Snider EJ, Degenhardt BF, Bukowski A, Johnson JC. Reliability of Tuffier's line as an anatomic landmark. Spine. 2008;33(6):161-5.

14. Williams PL, Warwick R (eds). Gray's Anatomy, 36th ed. Edinburgh: Churchill Livingstone; 1980.

15.Parate L, Manjunath B, Tejesh C, Pujari V. Inaccurate level of intervertebral space estimated by palpation: The ultrasonic revelation. Saudi J Anaesth. 2016;10(3):270-5.

16. Schlotterbeck H, Schaeffer R, Dow WA, Touret Y, Bailey S, Diemunsch P. Ultrasonographic control of the puncture level for lumbar neuraxial block in obstetric anaesthesia. $\mathrm{Br} \mathrm{J}$ Anaesth. 2008;100(2):230-4.

17. Whitty R, Moore M, Macarthur A. Identification of the lumbar interspinous spaces: Palpation versus ultrasound. Anesth Analg. 2008;106 (2):538-40.

18.Locks GD, Almeida MC, Pereira AA. Use of the ultrasound to determine the level of lumbar puncture in pregnant women. Braz J Anesth. 2010;60(1):13-9.

19. Lee AJ, Ranasinghe JS, Chehade JM, Arheart K, Saltzman BS, Penning DH, et al. Ultrasound assessment of the vertebral level of the intercristal line in pregnancy. Anesth Analg. 2011;113(3):559-64.

20. Chakraverty R, Pynsent P, Isaacs K. Which spinal levels are identified by palpation of the iliac crests and the posterior superior iliac spines? J Anat.2007;210(2):232-6.

21.Duniec L, Nowakowski P, Kosson D, Łazowski T. Anatomical landmarks based assessment of intravertebral space level for lumbar puncture is misleading in more than $30 \%$. Anaesthesiol Intensive Ther. 2013;45(1):1-6. 